\title{
Forecast on 2030 Vietnam Electricity Consumption
}

\author{
Vu H. M. Nguyen \\ Faculty of Electrical and Electronics Engineering \\ HCMC University of Technology and Education \\ Ho Chi Minh City, Vietnam \\ vuminh.1974@gmail.com
}

\section{Cuong V. Vo}

Faculty of Electrical and Electronics Engineering HCMC University of Technology and Education Ho Chi Minh City, Vietnam cuongvv@hcmute.edu.vn

\author{
Khanh T. P. Nguyen \\ Department of Research and Development \\ Global Electrical Technology Corporation \\ Ho Chi Minh City, Vietnam \\ phuckhanh180388@gmail.com
}

Binh T. T. Phan

Faculty of Electrical and Electronics Engineering HCMC University of Technology

Ho Chi Minh City, Vietnam

thanhbinh055@yahoo.com

\begin{abstract}
The first but very significant step in electricity system planning is to make an accurate long-term forecast on electricity consumption. This article aims to forecast the consumption for the Vietnam electricity system (GWH) up to 2030. An econometric model with the Cobb Douglas production function is used. The five variables proposed in the forecasting function are GDP, income, population, proportion of industry and service in GDP, and number of households. The forecasting equation is tested in terms of stationary and co-integration to choose meaningful variables and to eliminate the minor ones which account for none or small impacts on the forecast. The results show that: (1) the qualified forecasting equation only includes 3 major variables: the per capita income, the population, and the number of households, (2) with the medium income scenario, the forecasting consumptions in $2020,2025,2030$ are 230,195 GWH, 349,949 GWH, 511,268 GWH respectively. (3) The GDP and the proportion of industry and service in GDP do not make major impacts on this forecasting in Vietnam. The method and the result of this article are likely a typical example of forecasting electricity consumption in developing countries which have a transforming economy similar to that in Vietnam.
\end{abstract}

Keywords-long-term; forecasting; electricity; consumption; econometric; model; Cobb Douglas; production; function; Vietnam

\section{INTRODUCTION}

One of the most important requirements in national electricity system planning is to forecast the long-term electricity consumption for more than 5 or 10 years. The accuracy of the forecast makes a significant contribution to building up an economically optimal scenario for electricity system planning. In fact, it is very challenging to accurately estimate the long-term electricity consumption for the reason that the far-future (more than 5 years) consumption is dependent on some factors such as the GDP growth rate, the population, the transforming of economy structure, the electricity price, the level of applying scientific and technological advances in efficiently using energy, the electricity consumers' behavior and the climate change.
Vietnam is one of the few countries which experienced GDP growth rate more than $6 \%$ per year over the last 20 years. As a result, the electricity consumption increases by $15 \%$ annually. In 2010 the electricity consumption for more than 5 years ahead was simply predicted by using the value of the elasticity coefficient between the electricity growth rate and the GDP, whose value is 2 . However, there have been some considerable gaps between forecasting and actual consumption from 2010 to 2015 [1]. The purpose of this article is to forecast Vietnam's electricity consumption up to 2030 with high reliability by applying the scientific forecasting method which is popular in other developing countries. To make a forecast on long-term electricity consumption, developing countries usually focus on 2 main methods: (1) to predict by using time-series models (TSMs), and (2) to predict by using Artificial Neutral Networks (ANNs). Recently, in [2], authors utilized the mean absolute percentage error (MAPE) and the coefficient of determination $\left(\mathrm{R}^{2}\right)$ to point out that the TSM method brings more accurate predictions in comparison with ANNs method. A new prediction method named Newton was also introduced with promisingly higher accuracy. It should take more time to verify this new method.

This article uses econometric model - the econometric approach combines economic theory and statistical techniques for forecasting electricity consumption. The approach estimates the relationship between electricity consumption and factors influencing the consumption. The relationships are estimated by the TSM method. The most frequently used model is that of Cobb Douglas production function. It is widely utilized in researches from Malaysia [3], Pakistan [4], and China [5]. The common method shared by these researches is to investigate the influential factors or variables impacting the forecast result. In other words, it means to find the independent variables of the equation. Then, the past time-series data of variables are utilized to verify the proposed forecasting equation with major variables. Features of a transforming economy in developing countries which are taken into account as variables in this article are: (1) GDP, (2) income, (3) population, (4) proportion 
of industry and service in GDP, and (5) number of households. The input data are collected from 1990 to 2015.

\section{METHOD AND DATA}

\section{A. Applying Cobb Douglas Production Function}

Non-linear form of Cobb Douglas production function is given below:

$$
E C_{t}=\varphi G_{t}^{\beta_{1}} P_{t}^{\beta_{2}} I_{t}^{\beta_{3}} X_{t}^{\beta_{4}} H_{t}^{\beta_{5}}
$$

where $E C_{t}$ is electricity consumption in year t. $G_{t}, P_{t}, I_{t}, X_{t}$ and $H_{t}$ denote GDP, population, income, proportion of industry and service in GDP, and number of households, in the year t, respectively. The technological parameter is indicated by $\varphi . \beta_{\mathrm{i}}$ are returns to scale linked with the five above variables. By logarithmizing the two sides of (1), a linear function emerges:

$$
\ln E C_{t}=\beta_{0}+\beta_{1} \ln G_{t}+\beta_{2} \ln P_{t}+\beta_{3} \ln I_{t}+\beta_{4} \ln X_{t}+\beta_{5} \ln H_{t}
$$

\section{B. Testing}

There are many methods to test econometric models with the same purpose - to establish a prediction equation with the highest accuracy. For researches proving the causality between variables, the date in time series should be stationary tested (Augmented Dickey Fuller (ADF) or Phillips-Perron (P-P)) to avoid the spurious regression. After stationary test, the causality between variables is proven by using Granger causality test. For forecasting purpose, stationary test only is enough.

\section{1) Stationary Test}

In order to ensure the sustainability of the forecasting function, the stationary tests by using ADF unit root test and P$\mathrm{P}$ unit root test are conducted. If there are any non-stationary series, the first difference of the series is calculated and eliminating inappropriate variables is done. If all series are non-stationary, calculating the first difference of all variables, then removing the primary features of the series leads to low $\mathrm{R}^{2}$ in regressing. The low $\mathrm{R}^{2}$ means low prediction accuracy. Therefore, the co-integration test is conducted to avoid low $\mathrm{R}^{2}$.

\section{2) Cointegration Test}

Authors in [6] supposed the linear combination between non-stationary time series can be a stationary series and these non-stationary time series are co-integrated. The non-stationary linear combination is called co-integration equation and can be explained as the balance relationship between variables in longterm. Therefore, if variables co-integrate, regression can be conducted. In this article, Johansen trace test is utilized to test the co-integration. In the trace test (T-test), there are some hypotheses $\mathrm{H}_{0}$ listed as follows: "None", means there is no cointegration; "At most $1 ; 2 ; 3 \ldots$ ", means there are 1 , or $2,3 \ldots$ co-integrations. To decide if we should reject or accept hypothesis $\mathrm{H}_{0}$, trace statistic value and critical value of $5 \%$ are compared. If trace statistic $<$ critical value, then $\mathrm{H}_{0}$ is accepted. If trace statistic $>$ critical value, then $\mathrm{H}_{0}$ is rejected.

\section{3) R2 test}

In addition to stationary and co-integration tests, the research also tests the possibility and eliminates inappropriate variables of prediction equation on the base of two values of $R^{2}$. The high value of $R^{2}$ is a signal for intensive relationship.

\section{4) Eliminating inappropriate variables}

p-value is used to eliminate inappropriate variables. p-value is the lowest value of $\alpha$ through which the test result is statistically meaningful. The use of $p$-value to test the hypothesis is:

$$
\text { Reject } \mathrm{H}_{0} \text { if } \mathrm{p} \text {-value }<\alpha(\alpha=0.05) \text {. }
$$

After testing and eliminating inappropriate variables, a qualified forecasting equation to be proposed.

\section{Data}

\section{1) $G D P$}

Vietnam is one country that has experienced annual GDP growth rate of about $6.5 \%$ for the last 20 years. There are 3 scenarios of GDP growth rate of Vietnam up to 2030 [1]. Because of low GDP growth rate archived in recent years, the low scenario of GDP growth rate is taken into account in this article. It is likely that the consumption for electricity continues to increase sharply. It is shown that there is partly relationship between the GDP and the electricity consumption. The GDP in Vietnam is extracted from the World Bank data [7].

\section{2) Income}

Per capital income and the electricity consumption tend to be positively correlated. As the income increases, families have a tendency to purchase more electrical devices to satisfy their needs. For instances, at a certain level of income, they do not buy air conditioners and heaters. However, when the income reaches a higher level, after considering if they afford paying the electricity consumption, they purchase these devices to make their life more comfortable. As a result, the electricity consumption in that households rises [9]. Therefore, the per capital income is taken into account in this research. Data is extracted from the World Bank data (Atlas method) [7].

\section{3) Population}

The population growth rate in Vietnam is around $1.08 \%$ [7]. If there is a variable impacting on the electricity consumption, it is the population. The population increases, which enlarges power consumption. The population data are provided by the general statistics office of Vietnam [8].

\section{4) Number of Households}

The household separation leads to the increasing consumption for home electric appliances. It creates not only increase of electricity consumption in human livelihood but also that in the industry sector for manufacturing these 
appliances. Authors in [10] mention "Households energy consumption accounts for a large share of total energy consumption". However, there is a problem in data collecting that Vietnam and other developing countries encounter. It is the fact that the household data in Vietnam is not fully recorded. This requires establishing a method of calculating the number of households in Vietnam. The household data in Vietnam is scanty and un-intensive. In the years 1999, 2004 and 2009, the accurate numbers of households are 16.66, 19.01 and 22.44 million, respectively. Recognized as the official figures by Vietnam and The United Nations, these numbers are the results from the investigation on population and housing $[8,9]$. Moreover, the increasing and decreasing rates of number of households are also important parameters to calculate the numbers of households in the upcoming years. According to [8], the number of households in Vietnam 2014 is 24.27 million, two times that of 25 years ago (1/4/1989), one-and-ahalf time that of 15 years ago (1/4/1999), and nearly 2 million households higher than that in 1st April 2009. During the 20092014 period, the average increasing rate of households is $1.6 \%$ per year period. Recorded by Helgi Library, the number of households in Vietnam reached 26.9 million in 2016, increasing by $2.43 \%$ compared with that of the previous year [11]. Table I shows the number of households in Vietnam.

The comparison between Vietnam and other countries should be made to figure out the similarities in the average size of a household. The average size of Vietnam households in 1999 was 4.6 people/household, equivalent to that of Thailand in 1990 (4.62 people). According to the Thailand Development Research Institute, the size of Thailand's households changed throughout the years as follows: 1985: 4.98, 1990: 4.62, 1995: 4.27, 2000: 3.96, and 2005: 3.7. According to the National Statistical Office of Thailand, the number of households in Thailand reached 20.6 million in 2016. This increase accounts for $0.205 \%$, compared with that of the previous year. The number 20.6 million in 2016 is the highest, while the lowest is 0.6 million in 1960. In comparison with Thailand, those figures of Cambodia and Malaysia respectively are 3.34 million and 7.30 million [11]. According to The Department of Statistics in Malaysia, in 2016, the number of households in Malaysia reached 7.30 million, a rise of $1.74 \%$, compared with the previous year. This figure is the highest, while the lowest was 1.50 million in 1960. Compared with other neighbor countries of Malaysia, the numbers of households in 2016 were respectively 3.34 million in Cambodia, 1.26 million in Singapore, 20.6 million in Thailand, and 26.9 million in Vietnam [11]. It is easily recognized that there are geographic and socio- economic similarities between Vietnam, Thailand and Malaysia. Even in Japan, a developed country, the number of households keeps increasing at nearly $1 \%$ /year, while, population has been decreasing [11]. The statistical charts of the household growth in these countries tend to have exponential shapes. Based on the data in Table I, the trend line has the exponential shape shown in Figure 1. The trend line equation is:

$$
y=4.85 E-23 e^{2.71 E-0.2 x}
$$

TABLE I. NUMBER OF HOUSEHOLDS $[8,9]$ (MILLIONS)

\begin{tabular}{|c|c|c|c|c|c|}
\hline Year & $\mathbf{1 9 9 9}$ & $\mathbf{2 0 0 4}$ & $\mathbf{2 0 0 9}$ & $\mathbf{2 0 1 4}$ & $\mathbf{2 0 1 6}$ \\
\hline & 16.66 & 19.01 & 22.44 & 24.27 & 26.9 \\
\hline
\end{tabular}

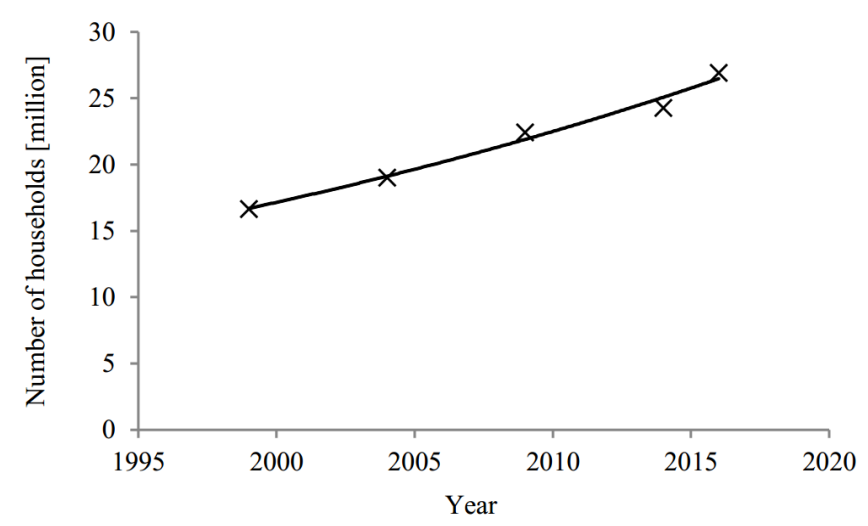

Fig. 1. The trend line of the number of households.

The household data from 1990 to 2015 are shown in Table II. Using the trend line, the prediction on the number of households in the future is shown in Table III.

TABLE II. THE NUMBER OF HOUSEHOLDS CALCULATED BY THE ARTICLE (MILLIONS)

\begin{tabular}{|c|c|c|c|c|c|c|c|}
\hline Year & $\mathbf{1 9 9 0}$ & $\mathbf{1 9 9 1}$ & $\mathbf{1 9 9 2}$ & $\mathbf{1 9 9 3}$ & $\mathbf{1 9 9 4}$ & $\mathbf{1 9 9 5}$ & $\mathbf{1 9 9 6}$ \\
\hline & 12.79 & 13.14 & 13.50 & 13.87 & 14.25 & 14.64 & 15.05 \\
\hline Year & $\mathbf{1 9 9 7}$ & $\mathbf{1 9 9 8}$ & $\mathbf{1 9 9 9}$ & $\mathbf{2 0 0 0}$ & $\mathbf{2 0 0 1}$ & $\mathbf{2 0 0 2}$ & $\mathbf{2 0 0 3}$ \\
\hline & 15.46 & 15.88 & 16.66 & 16.77 & 17.23 & 17.70 & 18.19 \\
\hline Year & $\mathbf{2 0 0 4}$ & $\mathbf{2 0 0 5}$ & $\mathbf{2 0 0 6}$ & $\mathbf{2 0 0 7}$ & $\mathbf{2 0 0 8}$ & $\mathbf{2 0 0 9}$ & $\mathbf{2 0 1 0}$ \\
\hline & 19.01 & 19.20 & 19.73 & 20.27 & 20.83 & 22.44 & 21.99 \\
\hline Year & $\mathbf{2 0 1 1}$ & $\mathbf{2 0 1 2}$ & $\mathbf{2 0 1 3}$ & $\mathbf{2 0 1 4}$ & $\mathbf{2 0 1 5}$ & & \\
\hline & 22.59 & 23.21 & 23.85 & 24.27 & 25.18 & & \\
\hline
\end{tabular}

TABLE III. THE NUMBER OF HOUSEHOLDS IN THE FUTURE (MILLIONS)

\begin{tabular}{|c|c|c|c|}
\hline Year & $\mathbf{2 0 2 0}$ & $\mathbf{2 0 2 5}$ & $\mathbf{2 0 3 0}$ \\
\hline Forecast number of households & 28.83 & 33.02 & 37.81 \\
\hline
\end{tabular}

\section{5) Proportion of Industry and Service in GDP}

In addition to the human livelihood, the proportion of industry and service in GDP are also sectors accounting for a large share of electricity consumption. A feature of a transforming economic in a developing country like Vietnam is that this proportion increases. Relevand data are shown in Table IV [1].

\section{6) Collecting Data in Time Series of 1990-2015}

After analyzing factors likely to influence the electricity consumption in Vietnam, the past data of the factors are collected. With full, accurate data and long enough time series, the equation predictions are more exact. According to $[12,13]$, if $\mathrm{n}$ the data in time series and $\mathrm{k}$ the independent variables in the model, then: $\mathrm{n}-\mathrm{k}>20$. As mentioned above, the chosen variables include the GDP, the income, the population, the number of households, the proportion of industry and service. Therefore, the forecasting equation contains 5 independent variables and: $n>20+5$. This study selects the time series from 
1990 to 2015 . The time series is relatively long enough variable including 26 values (equivalent to 26 years) to conduct testing. In addition to the domestic statistical data, the country has the chance to assess those data from international organizations. Table IV presents the relevant data.

TABLE IV. SUMMARY OF INPUT DATA

\begin{tabular}{|c|c|c|c|c|c|c|}
\hline Year & 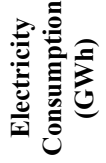 & 商总 & 产甶 & 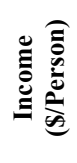 & 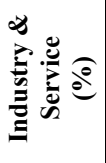 & 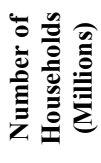 \\
\hline 1990 & 8,678 & 6.47 & 66,017 & 130 & 61.3 & 12.79 \\
\hline 1991 & 9,152 & 9.61 & 67,242 & 110 & 59.5 & 13.14 \\
\hline 1992 & 9,654 & 9.87 & 68,450 & 130 & 66.1 & 13.50 \\
\hline 1993 & 10,665 & 13.18 & 69,645 & 170 & 70.1 & 13.87 \\
\hline 1994 & 12,284 & 16.29 & 70,825 & 200 & 72.6 & 14.25 \\
\hline 1995 & 14,636 & 20.74 & 71,996 & 260 & 72.8 & 14.64 \\
\hline 1996 & 16,946 & 24.66 & 73,157 & 310 & 72.2 & 15.05 \\
\hline 1997 & 19,151 & 26.84 & 74,307 & 350 & 74.2 & 15.46 \\
\hline 1998 & 21,665 & 27.21 & 75,456 & 360 & 74.2 & 15.88 \\
\hline 1999 & 23,739 & 28.68 & 76,597 & 370 & 74.6 & 16.66 \\
\hline 2000 & 26,745 & 33.64 & 77,631 & 400 & 77.3 & 16.77 \\
\hline 2001 & 30,187 & 35.29 & 78,621 & 430 & 78.5 & 17.23 \\
\hline 2002 & 34,073 & 37.95 & 79,538 & 460 & 78.7 & 17.70 \\
\hline 2003 & 38,461 & 42.72 & 80,467 & 510 & 79.1 & 18.19 \\
\hline 2004 & 43,414 & 49.42 & 81,436 & 590 & 80.0 & 19.01 \\
\hline 2005 & 49,008 & 57.63 & 82,392 & 680 & 80.7 & 19.20 \\
\hline 2006 & 53,845 & 66.37 & 83,311 & 760 & 81.3 & 19.73 \\
\hline 2007 & 59,159 & 77.41 & 84,219 & 850 & 81.3 & 20.27 \\
\hline 2008 & 64,998 & 99.13 & 85,119 & 1,000 & 79.6 & 20.83 \\
\hline 2009 & 71,415 & 106.01 & 86,025 & 1,120 & 80.8 & 22.44 \\
\hline 2010 & 78,466 & 115.93 & 86,933 & 1,270 & 69.1 & 21.99 \\
\hline 2011 & 94,658 & 135.54 & 87,860 & 1,390 & 69.0 & 22.59 \\
\hline 2012 & 105,474 & 155.82 & 88,809 & 1,550 & 70.8 & 23.21 \\
\hline 2013 & 115,069 & 171.22 & 89,760 & 1,740 & 71.9 & 23.85 \\
\hline 2014 & 128,435 & 186.20 & 90,729 & 1,900 & 72.3 & 24.27 \\
\hline 2015 & 141,800 & 193.60 & 91,704 & 1,990 & 73.0 & 25.18 \\
\hline
\end{tabular}

\section{RESULTS}

\section{A. Converting Independent Variables}

The series of input data are converted into natural logarithms listed in Table V.

\section{B. Testing}

\section{1) Stationary test}

The stationary test results are shown in Table VI. It is shown that all $p$-values are larger than $\alpha(\alpha=0.05)$, except for the population variable $\left(\ln P_{t}\right)$ when P-P test is conducted. In other words, all variables are not stationary. Therefore, the cointegration test is to be conducted instead of calculating the first difference.

\section{2) Co-integration test}

The co-integration test results are shown in Table VII. After the test, we accept the hypothesis $\mathrm{H}_{0}$. There are three cointegrations with trace statistic method.

\section{3) Testing $R 2$ and p-value}

After the co-integration test, the coefficients of (2) are calculated and the results are shown in Table VIII. The condition for choosing the coefficients of equation is that the $\mathrm{R}^{2}$ almost equals to 1 and $\mathrm{p}$ - values of all variables are less than 0.05 . In Table VIII, R squared $\left(\mathrm{R}^{2}\right.$ testing $)=0.997953$. It means that $99.8 \%$ of dependent variables have impacts on independent variables. However, due to the fact that the $p$-value is above 0.05 , then, $\ln G_{t}$ is removed.

TABLE V. CONVERTING INDEPENDENT VARIABLES INTO NATURAL LOGARITHMS

\begin{tabular}{|c|c|c|c|c|c|c|}
\hline Year & $\ln \left(\boldsymbol{E}_{\boldsymbol{t}}\right)$ & $\ln \left(\boldsymbol{G}_{\boldsymbol{t}}\right)$ & $\ln \left(\boldsymbol{P}_{\boldsymbol{t}}\right)$ & $\ln \left(\boldsymbol{I}_{\boldsymbol{t}}\right)$ & $\ln \left(\boldsymbol{X}_{\boldsymbol{t}}\right)$ & $\ln \left(\boldsymbol{H}_{\boldsymbol{t}}\right)$ \\
\hline 1990 & 9.07 & 1.87 & 11.10 & 4.87 & 4.12 & 2.55 \\
\hline 1991 & 9.12 & 2.26 & 11.12 & 4.70 & 4.09 & 2.58 \\
\hline 1992 & 9.18 & 2.29 & 11.13 & 4.87 & 4.19 & 2.60 \\
\hline 1993 & 9.27 & 2.58 & 11.15 & 5.14 & 4.25 & 2.63 \\
\hline 1994 & 9.42 & 2.79 & 11.17 & 5.30 & 4.28 & 2.66 \\
\hline 1995 & 9.59 & 3.03 & 11.18 & 5.56 & 4.29 & 2.68 \\
\hline 1996 & 9.74 & 3.21 & 11.20 & 5.74 & 4.28 & 2.71 \\
\hline 1997 & 9.86 & 3.29 & 11.22 & 5.86 & 4.31 & 2.74 \\
\hline 1998 & 9.98 & 3.30 & 11.23 & 5.89 & 4.31 & 2.77 \\
\hline 1999 & 10.07 & 3.36 & 11.25 & 5.91 & 4.31 & 2.81 \\
\hline 2000 & 10.19 & 3.52 & 11.26 & 5.99 & 4.35 & 2.82 \\
\hline 2001 & 10.32 & 3.56 & 11.27 & 6.06 & 4.36 & 2.85 \\
\hline 2002 & 10.44 & 3.64 & 11.28 & 6.13 & 4.37 & 2.87 \\
\hline 2003 & 10.56 & 3.75 & 11.30 & 6.23 & 4.37 & 2.90 \\
\hline 2004 & 10.68 & 3.90 & 11.31 & 6.38 & 4.38 & 2.94 \\
\hline 2005 & 10.80 & 4.05 & 11.32 & 6.52 & 4.39 & 2.96 \\
\hline 2006 & 10.89 & 4.20 & 11.33 & 6.63 & 4.40 & 2.98 \\
\hline 2007 & 10.99 & 4.35 & 11.34 & 6.75 & 4.40 & 3.01 \\
\hline 2008 & 11.08 & 4.60 & 11.35 & 6.91 & 4.38 & 3.04 \\
\hline 2009 & 11.18 & 4.66 & 11.36 & 7.02 & 4.39 & 3.11 \\
\hline 2010 & 11.27 & 4.75 & 11.37 & 7.15 & 4.24 & 3.09 \\
\hline 2011 & 11.46 & 4.91 & 11.38 & 7.24 & 4.23 & 3.12 \\
\hline 2012 & 11.57 & 5.05 & 11.39 & 7.35 & 4.26 & 3.14 \\
\hline 2013 & 11.65 & 5.14 & 11.40 & 7.46 & 4.28 & 3.17 \\
\hline 2014 & 11.76 & 5.23 & 11.42 & 7.55 & 4.28 & 3.19 \\
\hline 2015 & 11.86 & 5.27 & 11.43 & 7.60 & 4.29 & 3.23 \\
\hline & & & & & & \\
\hline
\end{tabular}

TABLE VI. STATIONARY TESTING OF THE FORECASTING EQUATION

\begin{tabular}{|c|c|c|c|c|}
\hline Variable & \multicolumn{2}{|c|}{ ADF Test } & \multicolumn{2}{c|}{ P-P Test } \\
\hline & T. statistic & Prob.value & T. statistic & Prob.value \\
\hline $\ln \mathrm{ECt}$ & 0.000867 & $*$ & -0.026761 & $*$ \\
\hline $\ln \mathrm{Gt}$ & -2.287395 & $*$ & -2.232903 & $*$ \\
\hline $\ln \mathrm{Ht}$ & 0.632598 & $*$ & 0.721125 & $*$ \\
\hline $\ln \mathrm{It}$ & -1.210096 & $*$ & -0.475247 & $*$ \\
\hline $\ln \mathrm{Pt}$ & -0.641799 & $*$ & -9.851650 & $* * *$ \\
\hline $\ln \mathrm{Xt}$ & -2.457299 & $*$ & -2.457299 & $*$ \\
\hline & & & $\begin{array}{r}* \text { Variables with p-value }>0.05 \\
* * \text { Variables with } 0.02<\mathrm{p}-\text { value }<0.05 \\
* * * \text { Variables with p-value }<0.02\end{array}$ \\
\hline
\end{tabular}

TABLE VII. CO-INTEGRATION TEST

\begin{tabular}{|c|c|c|c|}
\hline Hypothesized No. of CE(s) & $\begin{array}{c}\text { Trace } \\
\text { Statistic }\end{array}$ & $\begin{array}{c}\text { Critical } \\
\text { Value }\end{array}$ & Prob. \\
\hline None $^{*}$ & 179.6550 & 95.75366 & 0.0000 \\
\hline At most 1 * & 109.0413 & 69.81889 & 0.0000 \\
\hline At most 2 * & 52.81937 & 47.85613 & 0.0159 \\
\hline At most 3 & 27.25295 & 29.79707 & 0.0956 \\
\hline At most 4 & 9.796955 & 15.49471 & 0.2967 \\
\hline At most 5 & 0.530471 & 3.841466 & 0.4664 \\
\hline
\end{tabular}


The recalculation of the equation coefficients is shown in Table IX. Similarly, $\ln X_{t}$ is removed and the equation coefficients are again re-calculated. The result is shown in Table $X$, in which all $p$-values of variables in the equation reach $* * *$ level. In other words, all p-values are less than 0.02 (very qualified).

TABLE VIII. CALCULATION OF THE COEFFICIENTS OF (2)

\begin{tabular}{|c|c|c|c|c|}
\hline Variable & Coefficient & Std. Error & t-Statistic & Prob. \\
\hline $\mathrm{C}$ & -69.19764 & 8.675347 & -7.976353 & $* * *$ \\
\hline $\operatorname{lnGt}$ & -0.110864 & 0.083668 & -1.325048 & $*$ \\
\hline $\operatorname{lnHt}$ & 0.682145 & 0.164572 & 4.144974 & $* * *$ \\
\hline $\operatorname{lnIt}$ & 0.220460 & 0.087524 & 2.518847 & $* *$ \\
\hline $\ln \mathrm{Pt}$ & 6.937385 & 0.861815 & 8.049738 & $* * *$ \\
\hline $\ln \mathrm{Xt}$ & -0.357666 & 0.151796 & -2.356232 & $* *$ \\
\hline R-squared & 0.998899 & & & \\
\hline F-statistic & 3628.116 & & & \\
\hline $\begin{array}{c}\text { Prob } \\
\text { (F-statistic) }\end{array}$ & 0.000000 & & & \\
\hline AIC & -3.800512 & & & \\
\hline
\end{tabular}

TABLE IX. CALCULATION OF THE COEFFICIENTS (SECOND TIME)

\begin{tabular}{|c|c|c|c|c|}
\hline Variable & Coefficient & Std. Error & t-Statistic & Prob. \\
\hline $\mathrm{C}$ & -62.79885 & 7.335583 & -8.560853 & $* * *$ \\
\hline $\operatorname{lnHt}$ & 0.756167 & 0.157561 & 4.799209 & $* * *$ \\
\hline $\operatorname{lnIt}$ & 0.145212 & 0.067787 & 2.142167 & $* *$ \\
\hline $\ln \mathrm{Pt}$ & 6.327205 & 0.741462 & 8.533421 & $* * *$ \\
\hline $\operatorname{lnXt}$ & -0.283445 & 0.143599 & -1.973864 & $*$ \\
\hline R-squared & 0.998802 & & & \\
\hline F-statistic & 4377.180 & & & \\
\hline $\begin{array}{c}\text { Prob } \\
\text { (F-statistic) }\end{array}$ & 0.000000 & & & \\
\hline AIC & -3.793289 & & & \\
\hline
\end{tabular}

TABLE X. CALCULATION OF THE COEFFICIENTS (THIRD TIME)

\begin{tabular}{|c|c|c|c|c|}
\hline Variable & Coefficient & Std. Error & t-Statistic & Prob. \\
\hline $\mathrm{C}$ & -53.82916 & 6.125857 & -8.787205 & $* * *$ \\
\hline $\operatorname{lnHt}$ & 0.974249 & 0.119498 & 8.152860 & $* * *$ \\
\hline $\operatorname{lnIt}$ & 0.197233 & 0.066438 & 2.968668 & $* * *$ \\
\hline $\operatorname{lnPt}$ & 5.338763 & 0.581688 & 9.178048 & $* * *$ \\
\hline R-squared & 0.998580 & & & \\
\hline F-statistic & 5156.169 & & & \\
\hline $\begin{array}{c}\text { Prob } \\
\text { (F-statistic) }\end{array}$ & 0.000000 & & & \\
\hline AIC & -3.700022 & & & \\
\hline
\end{tabular}

\section{Eliminating Inappropriate Variables}

After the eliminating of $\ln G_{t}$ and $\ln X_{t},(2)$ becomes:

$$
\ln E C_{t}=\beta_{0}+\beta_{1} \ln P_{t}+\beta_{2} \ln I_{t}+\beta_{3} \ln H_{t}
$$

where $\beta_{0}, \beta_{1}, \beta_{2}$, and $\beta_{3}$ are $-53.829,5.339,0.197$, and 0.974 , respectively (see Table X). Equation (4) becomes:

$$
\ln E C_{t}=5.339 \ln P_{t}+0.197 \ln I_{t}+0.974 \ln H_{t}-53.829
$$

Equation (5) is the qualified forecasting equation.

\section{Forecast on Electricity Consumption to 2030}

Future values of population, income, and number of households are predicted and shown in Table XI. Using this data, the natural logarithms, and (5), Vietnam electricity consumption in the future can be forecasted. The results are shown in Table XII.

TABLE XI. FORECAST ON POPULATION, NUMBER OF HOUSEHOLDS AND INCOME

\begin{tabular}{|c|c|c|c|c|}
\hline Variable & Note & $\mathbf{2 0 2 0}$ & $\mathbf{2 0 2 5}$ & $\mathbf{2 0 3 0}$ \\
\hline Population & (thousands) [14] & 96,302 & 99,929 & 102,886 \\
\hline \multirow{2}{*}{$\begin{array}{c}\text { Income } \\
\text { (\$/year) [1] }\end{array}$} & Low scenario & 3,307 & 4,939 & 7,205 \\
\cline { 2 - 5 } & Medium scenario & 3,370 & 5,111 & 7,836 \\
\cline { 2 - 5 } & High scenario & 3,485 & 5,450 & 8,450 \\
\hline $\begin{array}{c}\text { Number of } \\
\text { households }\end{array}$ & (millions) & 29.89 & 34.49 & 39.79 \\
\hline
\end{tabular}

TABLE XII. FORECAST ON ELECTRICITY CONSUMPTION TO 2030 (GWH)

\begin{tabular}{|c|c|c|c|}
\hline Electricity Consumption & $\mathbf{2 0 2 0}$ & $\mathbf{2 0 2 5}$ & $\mathbf{2 0 3 0}$ \\
\hline Low income scenario & 229,341 & 347,597 & 502,882 \\
\hline Medium income scenario & 230,195 & 349,949 & 511,268 \\
\hline High income scenario & 231,722 & 354,404 & 518,923 \\
\hline
\end{tabular}

The results show that in the low income scenario, the electricity consumption in 2020 is around $229,241 \mathrm{GWH}$, in 2025 is around $347,597 \mathrm{GWH}$ and that in 2030 is 502,882 GWH. In the medium scenario, the electricity consumption in 2020 reaches $230,195 \mathrm{GWH}$, in 2025 is around $349,949 \mathrm{GWH}$ and that in 2030 is 511,268 GWH. Finally, in the high scenario, the electricity consumptions in 2020, 2025, and 2030 are 231,722 GWH, 354,404 GWH, and 518,923 GWH, respectively. With the income increase from about $2 \%$ in case of medium and low scenario in 2020 to about $9 \%$ in case of medium and low scenario in 2030, electricity consumptions increases from about $0.4 \%$ to about $1.7 \%$, respectively.

\section{CONCLUSION}

By using the econometric model with the Cobb Douglas production function, the proposed forecasting equation (1) is made with five variables: GDP, income, population, proportion of industry and service in GDP and number of households. After ADF, co-integration and $\mathrm{R}^{2}$ and $\mathrm{p}$-value tests, the qualified forecasting equation (5) has only three variables: income, population, and number of households. This means that GDP, and the proportion of industry and service in GDP do not make a major impact on this forecasting in Vietnam. This is quite a surprising result. The explanation for this can be that income increase is also followed by GDP increase and that the data set of GDP (1990-2015) may not be aligned with the proportion of industry and service in the GDP. The equation of the number of households for Vietnam is proposed by exponential function (3) which is the one of Thailand, Malaysia, and Japan. Electricity consumption in 2030 will be more than two times that of 2020, and more than 3 times that of $2016(159,450 \mathrm{GWH})$. This means that billions of US dollars per year will need to be invested to the power system of Vietnam. In details, in case of the medium income scenario, electricity consumption increase about $10 \%$ /year in 2017-2020, $8.4 \%$ year in $2021-2025$ and $6.8 \%$ /year in 2026-2030. This is 
quite a good trend, because the increasing is slowing down gradually compared with that of the previous period (20102015) which was $10 \%-15 \% / y e a r$. The method and the results of this research likely are a typical example for the forecasting of electricity consumption of those developing countries which have the same transforming economy with Vietnam.

\section{REFERENCES}

[1] Institute of Energy, EVN, Revised version of master plan No. VII for power system in Vietnam, 2015

[2] P. Ozoh, S. Abd-Rahman, J. Labadin, M. Apperley, "A comparative analysis of techniques for forecasting electricity consumption", International Journal of Computer Applications (0975 - 8887), Vol. 88, No. 15 , pp. 8-12, 2014

[3] A. K. Imtiaz, N. B Mariun, M. M. R. Amran, M. Saleem, N. I. A. Wahab, Mohibullah, "Evaluation and forecasting of long term electricity consumption for malaysia by statistical analysis", IEEE International Power and Energy Conference (PECon 2006), Putrajaya, Malaysia, pp. 257-261, November 28-29, 2006

[4] M. Shahbaz, H. H. Lean, "The dynamics of electricity consumption and economic growth: A revisit study of their causality in Pakistan”, Energy, Vol. 39, No. 1, pp. 146-153, 2012

[5] J. Yuan, C. Zhao, S. Yu, Z. Hu, "Electricity consumption and economic growth in China: Co-integration and co-feature analysis", Energy Economics, Vol. 29, No. 6, pp. 1179-1191, 2007

[6] R. F. Engle, C. W. J. Granger, "Co-integration and error correction: representation, estimation, and testing", Econometrica, Vol. 55, No. 2, pp. 251-276, 1987

[7] World Bank Data, available at: http://data.worldbank.org/country/ vietnam

[8] General Statistics Office of Vietnam, Master investigation on population and households 2009 - Vietnam, 2009

[9] General Statistics Office of Vietnam, Master investigation on populayion and households 2014 - Vietnam, 2014

[10] R. Raudjarv, L. Kuskova, "Energy consumption in households", , Quarterly bulletin of statistics Estonia, Vol. 2010, No. 1, pp. 21-28, 2010

[11] Helgi Library, "Number of Households in Vietnam", available at: http://www.helgilibrary.com/indicators/number-of-households/vietnam/, last access: $03 / 2018$

[12] S. B. Green, "How many subjects does it take to do a regression analysis?", Multivariate Behavioral Research, Vol. 26, No. 3, pp. 499510,1991

[13] B. G. Tabachnick, L. S. Fidell, Using Multivariate Statistics, California State University - Northridge, Pearson Education. Inc., 2007

[14] General Statistics Office of Vietnam, United Nations Fund for Population Activities (UNFPA), "Vietnam Population Projection 20142049”, 2016 